\title{
Passive solar design of mass housing: Ensuring environmental improvements at the planning stage for suburban housing
}

Received (in revised form): 27th October, 2006

\section{Jonathan Scott}

has worked in research and teaching for The Robert Gordon University on a variety of projects, developing his interests in the areas of environmental design, energy monitoring, lifecycle analysis, social and occupancy evaluation. He completed his PhD in the field of environmental design in 2004, and he has since been employed as a research fellow at The Robert Gordon University.

\section{Martin Edge}

is Director of the Environments for People Research Centre and Research Coordinator of the Scott Sutherland School of Architecture and Built Environment. Since 1998 he has developed the portfolio of Architecture and Built Environment research in RGU from practice-based projects to more mainstream European and Research Council funding. He has published around 80 papers on a wide range of subjects including sustainability, assistive technology, disability and rural planning and development issues.

\begin{abstract}
Richard Laing
is Reader at the Scott Sutherland School of Architecture and Built Environment and has extensive experience of research concerning the evaluation of greenspace, the use of computer modelling within urban landscapes, environmental valuation within built heritage conservation and the strategic use of research within urban planning processes. A Chartered Surveyor, he has previously undertaken research and consultancy work for the EC, Scottish Enterprise, the Scottish Executive and the EPSRC, and is currently undertaking further research commissions for NHS Estates and the ESRC.
\end{abstract}

Correspondence: Jonathan Scott, The Robert Gordon University, Scott Sutherland School of Architecture and Built Environment, Garthdee Road, Aberdeen AB10 7QB, UK; Tel: + 44 (0) 1224263710 ; Fax: + 44 (0) 1224263777 ; E-mail: j.r.scott@rgu.ac.uk

\begin{abstract}
The development of an Environmental Site Assessment tool is described which is designed to be used by planners and developers of speculative housing, for the appraisal of whole new housing developments. The aim of the tool is to establish the implications of trade-offs between passive solar designs and more conventional suburban housing, while achieving a particular site density target. The tool can determine what the effect of changing housing density will have upon a passive solar development. The whole life financial and environmental costs are then calculated accordingly for a housing project. Although the research has involved detailed analysis of building performance, the focus of the tool is on the footprint of the house and the early stage design of housing layouts. Thus, it can have an influence on passive solar performance from the earliest part of the planning process, even before the sketch design stage. The intention, with further development of the tool, is to provide a comparative analysis between dominant current approaches and emerging environmental methods of construction in housing developments. At this stage, the tool is a prototype which aims to simplify a focused range of complex planning issues to give an informed and best case scenario of anticipated costs and emissions over the lifecycle of housing developments. Although this tool is aimed at smoothing
\end{abstract}


the adoption of more sustainable housing practice during the planning stage, by providing discourse between local authority planners and the builders of housing developments, ultimately the main aim is to benefit the environment by reducing emissions and the homebuyer by reducing household energy costs and increasing comfort.

Journal of Building Appraisal (2006) 2, 207-222. doi:10.1057/palgrave.jba.2950041

\section{Keywords:}

housing layout, environmental assessment, value assessment, whole life costing

\section{INTRODUCTION}

Research is reported which investigated the use of passive solar design, as an exemplar of environmental design, for whole developments, as a means of overcoming the resistance to adopting sustainable housing practices. With the emphasis in current housing construction on density rather than environmental objectives, there is a lack of expertise, both among planners and speculative developers, on the design of environmentally sensitive projects. It is argued that there is a need for a method that can assess the sustainability of the designs for a site at a very early stage in the process. With this in mind, the aim of this research was to produce a framework for an environmental site assessment tool for the optimisation of passive solar detached housing layouts in a development during the planning process. The framework tool is novel in the use of simple geometric shapes and forms during the conception of a housing development as a tool for comparing standard and optimised housing layouts with the proposed layout, using a whole lifecycle database system approach. The benefit of a tool during the conception of housing developments is in identifying, at an early stage, the potential of a specific site for various environmental strategies.

This product will be useful to planners in ascertaining the potential of, and providing detailed recommendations, for a site and could be used as a dialogue tool with housing designers. It is further argued that a system that can ascertain the potential of a site at an early stage of its design, can aid in the acceleration of the planning process. The paper is concluded with recommendations for further work to develop the system for practical application.

\section{THE NEED FOR LONG-TERM HOUSING GOALS}

Cutting edge projects have arguably encouraged, at a somewhat sedate pace, improvements in building standards demanded by legislation. This has culminated in improved thermal efficiency standards for building envelopes introduced in spring 2001 in England and Wales and 2002 in Scotland that were primarily aimed at reducing $\mathrm{CO}_{2}$ emissions. Such cutting edge projects have created homes that demand much less energy than their 'standard' contemporaries, or make use of renewable energy sources. Borer and Harris (1998), Kachadorian (1997), Yannas (1994b) offer examples. Many of these radical homes can be characterised as showcase developments, which employ all manner of stateof-the-art techniques, as well as sound, basic passive solar principles, to produce often expensive, prestige homes designed to demonstrate what is possible. The theory is that money will be saved over the lifecycle of the building.

The construction industry has a history of achieving short-term goals, without realising sustainable, long-term objectives for housing. The Urban Task Force was created partly to find 'radical solutions' to this problem (DETR, 1999), recommending changes 
predominantly to the planning stages for real, long-term sustainable benefits.

Environmental, ecological, or green design, as it has variously been called, is a means, if used appropriately, of helping to achieve sustainable, long-term housing goals. In northern latitudes, however, many low energy housing projects are developed at much lower densities than industry standards. The result is fewer houses on valuable land, a problem highlighted as a main issue causing urban decline by the DETR (1999), arguably contradictory for a sustainable development. The identification of the planning stage as an important time for making decisions about sustainability and the issue of density in high latitudes has been noted.

There is a growing belief, encouraged by government, that long-term goals should not be forgotten in favour of short-term monetary objectives. Initial cost will always be important and many of the showcase projects have a short-term flaw in that it has generally been perceived by the wider construction industry that there must be a monetary penalty when demonstration developments are transferred, in a somewhat diluted form, into the more affordable mass market. In addition, the non-financial benefits, which are often overlooked, are key issues that need to be fully incorporated. Whole life costing techniques, such as those described by Kirk and Dell'Isola (1995), are pivotal to any environmental impact or building appraisal of this nature. Future developments in lifecycle technologies and tools will, however, also include the non-financial aspects of an environmental assessment. This is particularly difficult with the complex and varying issues that surround sustainable designs, but life-cycle impact assessment of non-financial issues, such as described by Kishk and Pollock (2005) and Kishk (2002) will, in future, play central roles in appraising more sustainable housing developments.

The research reported here investigated the achievement of long-term housing objectives through the use of environmental design with significant emission reduction and cost benefits. It has used passive solar heating as an exemplar to develop a framework for an environmental site assessment tool for whole site appraisal during the conceptual and planning stage of housing developments.

\section{CURRENT MODES OF SPECULATIVE DEVELOPMENT}

A major problem in trying to encourage more environmentally sound design in speculative, mass housing, relates to the initial design approach taken by developers. Long before a project reaches the detailed design stage, the basic footprint of the development, which has direct impacts on the environmental performance, has, arguably, been decided purely on the grounds of optimising the sale value.

The typical footprint involves primarily detached dwellings on narrow streets with offstreet parking, set to high-density targets. In particular, constructors/developers currently build dense developments with narrow-fronted and detached or semi-detached housing primarily to suit market demand, with dwellings traditionally facing each other across a distribution road. This does not necessarily meet passive solar layout requirements. This research establishes that, on 43 proposed housing developments in the North East of Scotland, the density proposed using current methods of construction is, on average, 18 per cent greater than that required for an optimum passive solar development. In some cases, this is as high as 40 per cent. The findings of the project have implications for the assumption, often made in local and national policy, that maximising housing density is an appropriate environmental aim.

Previous studies into passive solar housing layouts, by the BRE (BRECSU, 1995, 1997), also indicate that there is some reluctance to adopt passive solar design principles fully, 
for a number of reasons. The fact that current housing development patterns can provide more homes on most sites compared to a more sustainable, passive solar development is a major factor against any form of alternative housing layout.

The reasons for not adopting alternative housing strategies is primarily due to two factors, the high cost of building land and the apparent market preference for detached housing. Current patterns of (particularly suburban) residential development focus on grouping homes with minimised footprints — detached (and sometimes semi-detached) dwellings that minimise road frontage while maximising density — within predetermined site boundaries. It may be surmised that the reasons for current patterns of development are not only derived from perceived market demands, but are compounded by government calling for higher housing densities, for example through the Urban Task Force (DETR, 1996). As a result, land values increase and building high-density developments becomes critical for developers. While on the face of it a high development density for detached homes can be seen as a basic requirement for 'sustainable' developments (in that less green-field land is built upon), such a narrow definition of sustainable development ignores aspects of the building performance. In particular, the energy performance of the building as a system (DETR, 2000); the site as a whole; and, the consequent reduction of pollutants.

In addition, there are few tools that can determine the performance of groups of buildings or housing layout appraisals. Current environmental strategies in 'green' or 'ecological' housing tend to focus on the individual building rather than the development as a whole (Marsh et al., 2001). This focus on individual buildings is reflected in the majority of housing assessment tools. These tools do not attempt to overcome the tensions between current mainstream building practice and sustainable development, which are both complex and far reaching (Edwards and Pawley, 2000).

\section{CHARACTERISTICS OF PASSIVE SOLAR DEVELOPMENT}

Passive solar design is a broad term for optimising the design of buildings through their orientation to achieve the best balance of solar gains and losses. At high northern latitudes this generally requires buildings to face approximately south. It is a holistic design method for reducing the need for non-renewable fuel (Balcomb, 1992; Kachadorian, 1997). International policies on low energy recognise passive solar as a free energy source and the extent to which you save in cost can be determined using a number of energy calculating tools (Marsh et al., 2001). It is unlikely that a solar heated home will be able to do without a conventional heating system, but it will reduce the energy dependency from non-renewable sources (DTI, 1999, 2000; EC, 2000). This free source of energy is not taken account of by most speculative housing developers, however, despite the monetary and non-monetary benefits it can provide for home owners.

Passive solar design incorporates a variety of energy conserving features. Where all these features are used, the greatest savings in terms of heating and emissions are possible and an appropriately designed passive solar home can reduce heating costs by up to 70 per cent (Deveci et al., 2000) and reduce emissions by similar proportions, thus benefiting both occupier and environment. In addition, Yannas (1994a) notes that passive solar design can provide greater comfort for home owners. Housing adopting passive solar design can, in future, take up active solar environmental strategies more suitably than houses randomly oriented. It is perhaps these last two points that make passive solar design desirable in most low energy designs. Marsh et al. (2001) elaborates on this point, discussing the idea that, with improved thermal standards legislated for, the focus in 
passive solar design has now moved away from heating demand in housing, and has moved more towards environmental impact and the long-term effect of pollutants.

In northern latitudes, to gain full year round solar access to a group of buildings, the spacing reduces the optimum density of housing sites. In addition, in northern latitudes passive solar considerations dictate the optimum building form and location of a development, as well as orientation. In real terms an ideal site, which complements a passive solar design, is not likely to occur in such latitudes. In short, passive solar housing developments cannot achieve the same high densities as more conventional housing developments, in northern latitudes, if the desired aim is to have full, year round solar access. This makes passive solar homes potentially less feasible for mass suburban housing, as they may reduce return on investment and the value of the land.

The idea of environmentally friendly, sustainable design is often perceived extraneously by many housing developers (Cullingworth and Nadin, 2002). These negative perceptions, such as the perception of high capital costs, need to be overcome before sustainable design principles can be applied to mass housing. Investigation into built developments provides evidence that passive solar projects provide better benefits to the home buyer and environment than current construction and layouts (Yannas, 1994a,b). Any environmental site assessment will need to overcome this reluctance and exhibit the wider benefits. This is where the affordability of simple passive solar designs can play an integral role, as it is this that makes passive solar design a better solution than some other design approaches to sustainability.

\section{SPECULATIVE HOUSING AND THE PLANNING SYSTEM}

The early planning stage of a development is the ideal time to adopt passive solar principles, but there are some key obstacles described by Yannas (1994a) namely; the lack of design information; credibility and applicability of passive solar principles; marketability of passive solar; lack of incentive from the government to adopt these technologies; perceived increase in the costs when these technologies are adopted and design (aesthetic) quality. In general, the planning profession is not concerned with or particularly well trained in the physical performance of buildings, yet decisions made at this stage can radically affect the performance of passive solar designs. In addition, planning officials have to deal with a whole series of environmental issues, of which the future physical and environmental performance of buildings may be low on the priority list. Housing developers therefore remain the driving force behind early planning decisions - decisions such as basic layout, quality, strategy, process, management and, importantly, density. Their housing strategy is economically driven, once the minimum building regulations and any stipulations of local planning authorities are achieved. This leads, in most cases, to increases in capital costs in the short term and the reduction of the potential to save heating costs and emissions in the long term, if sustainable practices are added at a later stage in the design process.

Across the construction industry in the UK suburban housing developers plan, design and build on very similar principles, arguably with limited innovation in housing (Blackler, 2002). This makes for the slow adoption of alternative housing designs and layouts, such as environmental design, among mainstream speculative developers where issues such as sustainability and green design can be marginalised (Blackler, 2002; Cullingworth and Nadin, 2002). These concerns, however, coupled with increased density for housing developments, are central to the objectives of the planning office and government (DETR, 1999; Cullingworth and Nadin, 2002). 
For a housing developer, if a sustainable project was to be developed, there is a perception that there is an additional monetary risk, which is forwarded onto the homebuyer, making this type of project less marketable. In short, the principal housing form of densely packed, detached homes built to minimum building regulation standard is the result of economic imperatives coupled to risk aversion. This short-term focus, although relevant, fails to take account of the long-term costs to the environment.

In addition, during the planning stage, environmental aspects of designs are often vague, leading to flaws in the decision-making process if professionals are not properly trained in environmental architecture or do not have access to this form of housing development appraisal. Bordass (2000) states that it is often difficult even for professionals well trained in environmental or 'green' design to differentiate between an environmentally friendly dwelling and one that merely claims to be. More information to aid decision making at this stage is required - both for short- and long-term decision making. An environmental site assessment tool, which appraises a site comparatively, based on simple building geometry and layout providing indicative costs, would be a useful tool to investigate the potential of a site at the initial stages.

Currently, the only time when a change can be made to the developer's planning strategy is at the planning consent stage. The adoption of environmental designs at this stage in speculative developments is, however, unlikely without further incentive. For an environmental design to be adopted, one incentive that a housing developer may find attractive would be a rapid planning consent. It is hoped that an easy to use, transparent tool such as the one developed in this research could speed up the planning consent for the housing developer, if passive solar or other 'green' design principles are adopted during the planning stage.

\section{DEVELOPING AN ENVIRONMENTAL SITE ASSESSMENT TOOL}

Local government, during the planning process, now encourages the use of tools to determine monetary costs and emissions as an indicator of a more sustainable design over current methods of construction (SAP and the Carbon Index Method for example). Other aspects of policy focus on energy conserving 'add-on', features, such as Photovoltaics. This emphasis is partial and does not cover every aspect of energy and material conservation. This approach, emphasising retro-fit solutions in a construction industry whose products have very long lives, may be a reasonable one, but the design of new housing and its relationship to the site is not easily incorporated into such policy. It is an aim of this research to explore other mechanisms for encouraging better environmental design through the application of policy during the early phases of new housing construction.

There is currently no decision-making tool designed for the planners of developments during the early stages of design, which can determine the environmental credentials of a design for an overall site and help decision makers to act appropriately. Currently, through the adoption of BRE accredited software that defines the 'Standard Assessment Procedure' (SAP) for a home, or through hybrid manual/mathematical methods, the energy costs and emissions associated with a home can be determined. Most developments contain more than one individual home however, and the grouping of dwellings, which is of greatest concern to planners yet is not part of established assessment methods, can have more environmental impact than the design of an individual home.

The research reported here developed a model for an environmental site assessment tool, which can advise the planners of developments as to the best case scenarios, for 
varying densities, on development sites. The aim is to encourage dialogue between the planners and builders of housing developments at an early stage, during the development of the basic 'footprint' of dwellings within the site. The product aims to overcome perceived barriers to the introduction of environmental design and introduce the development of environmental concepts earlier in the design process, when information on environmental issues is often vague. This product development is the foundation for the future development of an environmental site assessment tool for the planners of housing developments.

\section{THE RESEARCH METHODOLOGY}

The investigative phase of the development of the assessment tool involved four basic stages:

(1) Developing databases of the characteristics of housing types, with a view to establishing 'standard' and passive solar designs with which to populate sites. These databases form part of the completed tool.

(2) Site investigations to assess the characteristics of existing speculative housing developments on real sites.

(3) The assessment of performance of houses within hypothetical test sites in financial and energetic terms.

(4) Research into optimum methods of data representation for the results of the tool.

As stated previously, this is a tool to be used in the conceptual stages of a project. Aside from the physical characteristics of the site, very little definitive information on the buildings, their aesthetic design and their specification will be known at this stage. Therefore, a tool, which assesses a site's potential, needs to work from limited criteria such as simple shapes and building footprints.

To calculate costs the tool uses existing, familiar and readily available energy calculating software to calculate basic energy needs where required. Yannas (1994a) summarises the extent of knowledge on passive solar housing layouts. Beyond this, the environmental site assessment has developed the necessary technologies to determine the long-term costs and to exhibit the data output using the latest advances in software.

It is not possible to provide a southern orientation, for a variety of reasons, for all the dwellings in a layout, and this is where a balance between passive solar and thermal standards can be achieved. Yannas (1994a) suggests that, 'in all such cases a judgement will need to be made weighing the respective advantages and disadvantages of an offsouth orientation.' This tool determines the effect of any trade-off between standard and passive options.

\section{Databases of housing types and features}

Databases are used in the tool to make the process of house selection more straightforward. For this database to be devised, analysis of the housing types, size and form in Scotland was carried out. From this a database of passive solar alternatives was created. Based on a limited amount of selection criteria a user of the tool can select the housing type for a site based on the information in these databases to provide an informed yet simple comparative analysis on a site.

The databases contain enough information to mathematically determine, initially, overshadowing distances. The spacing between dwellings can then be determined. This is 
important as it informs the databases in the system what the footprint area of the building is. The tool will then determine site density for passive solar housing and compare this against the set standard which the developer and/or planning requires for the site. Informed decisions can then be made.

The reason for calculating the overshadowing distance based on the density of the site is so that the obstruction angle may be determined. If the obstruction angle is greater than the minimum midday solar altitude, then the site density is such that northerly buildings are obstructed from solar gain for part of the year (in the winter when heat gain is most needed). From this knowledge, a user may make three key decisions:

- Reduce site density and restart analysis.

- Proceed with investigation, and determine effect on (additional) heating load (information on changes to heating demand taken from a database).

- Make changes to housing forms to achieve site density.

\section{Preliminary site investigations}

The preliminary research on housing layout gathered information on new and proposed local housing sites in Aberdeenshire, chosen from the Aberdeenshire Local Plan, mainly focusing on detached, mid-range (3-4 bed) housing development in semi-urban areas. Focusing on this type of housing, in this location, provides for a worst case scenario and will act as exemplar when adopted in other locations using other house types. An analysis was carried out of variables such as height, footprint, area, topography and density of developments in order to optimise passive solar performance. In the north-east of Scotland, over-shadowing distances need to be calculated to allow for full year access to the sun, meaning that passive solar site densities are limited.

Comparison between existing and proposed sites against an optimised passive solar alternative was undertaken to analyse if significant differences in densities occur. Using a single passive solar house, one can determine the over-shadowing distance at particular latitudes by determining the solar altitude. This gives the distance from the apex of one house to the window level of the house to the north. By determining the 'shadow' footprint of the home, the area of a single passive solar plot, which would provide solar access to a dwelling throughout the year, can be determined. From this, the number of passive solar homes on a site can be determined and compared with the number of houses actually achieved or planned and the number of narrow frontage houses that could potentially fit on the site. This gives a quantitative measure of the potential difference between solutions using the different housing types. Research by BRECSU (1995), illustrated in Figure 1, demonstrates that spacing between housing increases exponentially in northerly latitudes, in particular when full, year round solar access is desired. Research into the housing in the North East of Scotland showed that, the average number of dwellings per hectare (dph) for speculative housing sites is around 19. Average dph for current speculative developments in the region is 24 , with many large sites designed to a significantly greater density.

\section{The assessment of housing performance}

The required data for the environmental site assessment are readily available and involves mathematically determining distances and angles to establish, for example, the accurate over-shadowing distance. Research into passive solar design in the 1970s and 1980s established the parameters surrounding passive solar and this tool has brought together 


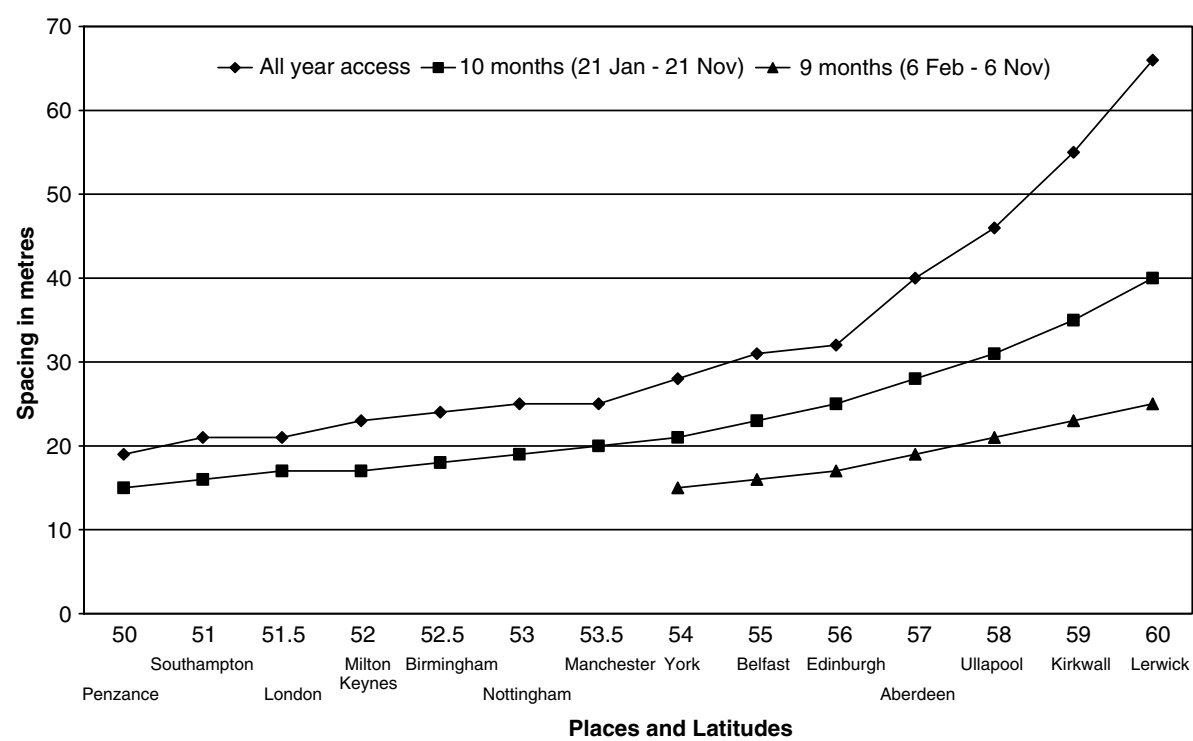

Figure I: Effect of solar altitude (expressed as spacing between housing) in northern latitudes (BRECSU, 1997)

the existing knowledge on the topic, described in Yannas (1994a). The tool also aims to ensure that this information is brought together in a user-friendly manner for those not familiar with the principles of passive solar design.

The key output of the analysis carried out by the tool is the determination of the costs, non-monetary and monetary, involved. Currently, the main costs determined are the long-term energy costs and emissions, and these are arrived at with the use of energy calculating software and LCC calculations based on those detailed by Kirk and Dell'Isola (1995). The software used to calculate costs can be inaccurate in comparison with historical data from existing buildings, but as a comparative analysis between standard and passive homes it provides decision-making statistics.

\section{Data presentation}

A visual display of the data represented in the framework tool for an environmental site assessment offers various advantages over other mathematical-based data representation techniques. Tufte (2001) notes that the visual display of complex ideas communicates with, 'clarity, precision, and efficiency' and this is important to illustrate cost and emission benefits of passive solar designs over current methods of construction. In addition, visual data representation can graphically portray more clearly each comparative option.

\section{DEVELOPMENT OF THE ENVIRONMENTAL SITE ASSESSMENT TOOL}

The tool itself focuses on six main areas. It is based around getting as much information into a database as possible, which then can lead to informative decision making. In addition, the tool will re-run itself and compare with pre-existing assessments for the same site - essentially measuring not just the three different types as highlighted in the methodology, but comparing them against current standards, optimised passive standards and also a range of selected passive solar alternatives. The six areas are as follows:

(1) site layout and planning;

(2) specific footprint details; 
(3) the orientation of housing;

(4) obstructions;

(5) selection of housing alternatives;

(6) whole lifecycle analysis.

The first four areas listed above, it should be noted, do not require specific expertise on the part of the user of the tool. All areas of the tool allow for some subjectivity and flexibility; however, the final two areas require some level of experience or expertise.

\section{The information on the housing development}

The environmental assessment tool assesses the basic topographical features and the planning of a development. The following sets of variables need to be input by the housing designer and user of the tool:

\section{Site location and development density}

For passive solar homes, site location is the first critical aspect of the design. The assessment tool assesses the effect that latitude has on any development and compares solar altitude with obstruction angle to determine any problem. Combined with this, the development density, in northern climates, has been analysed. This has determined that for higher latitudes passive solar developments become prohibited by overshadowing distances. Therefore, for passive solar developments to be adopted a method of coming to a form of 'trade-off' is needed, with the necessary analysis of the effect this has on physical aspects, such as space heating costs.

\section{Site geometry and topography}

A favourable site geometry and topography can make a significant difference to a passive solar home development and the assessment tool includes a calculation of the slope angle. A basic method of calculating slope angle is used in the assessment, but the slope angle is calculated using two dimensions only (for example, north to south), whereas factual sites are more undulating.

\section{Roads, green-space and access}

Roads and access to a site can take up to 15 per cent of a site, and add considerably to the construction costs of a housing development. Therefore, a method of determining the road width and type is included in the assessment tool. A site developer should consider varying aspects in relation to roads and access, including one way instead of two way road layout and/or centralised car parking reducing roads on the site. Similarly, greenspace is an important aspect of most housing developments, and within the tool alternative housing developments must adhere to green-space standards set by current standard speculative developments.

\section{Plot frontage and depth}

The assessment tool calculates the plot frontage and depth from basic geometrical shapes (footprints) taken from a database. These are used to determine overshadowing and obstruction angles, both of which are dependant on the site density.

\section{The use of housing databases in the tool}

The tool compares passive solar alternatives against a standard home - termed the base home. In order to establish the design of the base home, a database of the current 
typologies used by the main housing developers in the north east of Scotland was established. This allowed the creation of an average home for the north east of Scotland (the base home). As a comparative alternative an optimised passive solar home was derived by investigation of solar case studies at similar latitudes to Britain, as well as a case study situated in Aberdeen. In total, there are three basic variations on housing in the tool, defined as follows;

- Standard homes: Developments, as they stand, do not require the determination of spacing by the tool as they are set by the user. These homes meet building regulation minimum standards in thermal efficiency.

- Passive solar homes: These developments are chosen from a passive solar database and require the spacing to be determined on a north south axis, matching the density of the proposed (standard homes) development. By using energy calculating software, a range of passive solar homes, on an $\mathrm{m}^{2}$ basis, was derived to form an environmental housing database. The database has been integrated into the environmental site assessment tool so that costs and emissions can be obtained from this passive solar database, without any prior knowledge of how these buildings operate. These buildings can be selected from the database using simple specifications. A similar methodology was used by Turrent et al. (1981) to establish the effects of a range of benefits accrued by using passive solar, and this research uses a similar system, brought up to date to include recent building regulation changes, to establish the same benefits.

- Optimised passive solar homes: As a third option, each optimised passive solar home is spaced to gain the optimal performance in terms of passive solar gain for the entire year. This usually results, in northern latitudes, in a reduced density. To reiterate, the difference over the passive solar homes and standard homes above is that the density is not the same as for the standard homes.

In addition to the databases created for standard and passive housing types, databases have been embedded into the assessment procedure so as to select appropriate housing forms. These databases are needed to determine elements of simplified housing forms, such as storey height and house footprint, in order to establish key passive solar trade-offs between current methods of construction and passive solar. The database format for housing information has been incorporated into the tool to benefit, in the future, from the latest developments in whole life analysis methodologies such as those described by Kishk and Pollock (2005) and Kishk (2002).

Using the databases, the tool can determine the effect that changing the density has upon a passive solar development in terms of costs and the emissions. The aim is to establish the effect of the trade-off that is required for a passive solar development, in comparison to current methods of development, to fulfil a site's density target.

The passive solar house type database may, with further development, also include a variety of environmental elements to determine the trade-offs required to maximise density. This database allows a certain degree of control of the specification of various aspects of passive solar. The tool allows the selection of passive solar home by giving the user a range of options, which include insulation, air-tightness, percentage glazing and type of heating. Once selected, the passive solar design can then be placed into the prescribed site and costs can be determined. The passive solar database calculates data on each house alternative, using BRE accredited software used to calculate the SAP rating. This software has a number of limitations but allows the collating of data on each house 
type simply and in an easily recognised and familiar way. Some rules and assumptions were made to create this database.

- The only variables that change to create the passive solar database are the amount of glazing (primarily south-facing glazing), glazing type and height, thermal efficiency and air-tightness. The database converts this data into a unit rate so that it may be applicable to homes other than of the size specified.

- The elements of the design that remained the same were the energy type (gas) and the boiler efficiency (an efficient and modern 83 per cent for each alternative). All appliances and mechanical ventilation are identical.

- It was assumed that the heating system specified for each alternative did not deteriorate in efficiency over its lifecycle and that the system used did not lose efficiency.

- In most passive solar homes, the glazing is down to ground level, but in high-density sites you may not gain any solar gain with a major proportion of the glazing towards the foot of the window. A more favourable spacing distance (and therefore greater density on a site as a whole) may be achieved if the glazing is raised above ground level using standard height windows, which also reduces the cost of the glazing. It should be noted that in northern latitudes, even small but favourable changes to both the sill height and the slope angle can provide more solar gain for longer. These small changes are exponentially more influential in northern latitudes and should not be overlooked.

The orientation of each house type is calculated. The tool also considers housing on the southern boundary of the site separately. If the number of homes on the southern boundary is known, for passive solar purposes only, these homes are not overshadowed by interior obstructions unless there are exterior obstructions to solar access to these homes. These may be topographical features or man made structures of any kind, the height of which needs to be known. The distance to the object also needs to be (approximately) calculated. In addition, the number of homes that this feature affects needs to be known, although this assumes that the site layout has also been determined.

From Yannas (1994a), which used the 1991 building regulations, the difference between facing due south compared to east (or west) equates to approximately 15 per cent in reduced heating demand. If the same analysis with the 2002 (Scotland) changes to the thermal efficiency of the building regulations is undertaken, the (approximate) result is that these values will be reduced by almost half. Insulation, therefore, has a significant role in making a passive solar home efficient. It is also less dependant on orientation, and it is logical to assume that on sites where due south orientation is more difficult to achieve a compensational increase in insulation would ensure that passive solar could still be used, although the risk of overheating (or under-heating) would need to be assessed.

\section{Financial considerations in the tool}

The costs in the analysis are not only based on the energy elements of each home, but also on the whole life costs. The assessment procedure includes an exemplar lifecycle costing element in the analysis, similar to that described by Kirk and Dell'Isola (1995). At this stage, the lifecycle cost component of the tool is restricted, to be included in the future development of the tool.

The life-cycle information determined in the last area of the conceptual tool will provide a long-term perspective. This area focuses on the financial aspects, analysis period, initial and running costs. It does not currently incorporate non-financial costs, such as described by Kishk and Pollock (2005). The tendency for the government is to 
focus on the financial benefits and costs, for example using the standard assessment procedure (SAP) and the Carbon Index method (CI), which are quickly becoming policy in planning departments in the north east of Scotland. Both of these methods are used in the tool, but the wider implications for the environment are an area for future development. Future evolutions of this assessment procedure will see a more integrated role using whole life costs in determining the monetary costs and benefits of various options. In addition, the latest life-cycle analysis methodologies will be used to determine the non-financial costs of sustainable design (Kishk and Pollock, 2005).

\section{Data representation by the tool}

For useful interpretation, the financial data described previously needs to be presented in a user friendly and descriptive manner. Current energy calculating tools tend not to provide accessible feedback to the user in a friendly manner. The appraisal of housing developments involves far more complex issues than for an individual home, which is complex within itself. Data representation must, therefore, be in an accessible, useful and easily visualised manner.

The output of this environmental site assessment tool is a graphical model (of emissions against whole life costs), which has been developed to compare projects. The output is scaled between the conventional alternative (the base home in this case) and the optimised passive solar design. The site will be evaluated against current government objectives, most notably the commitment made by the government to the Kyoto Protocol.

The graphical model can allow the user to visualise the potential benefits of alternative design strategies, simply and with maximum user friendliness. The key policy commitments of reducing $\mathrm{CO}_{2}$ emissions by 20 per cent, and reducing domestic energy use by 30 per cent by 2010, all part of the obligation to meet the Kyoto Protocol, are the key targets alluded to in the graphical model.

The environmental site assessment is not intended to 'predict the future', as it is based on current information and can only make future predictions within approximate ranges. What this site assessment tool can do is compare conventional designs against various environmental designs, and give the planner of a housing development feedback regarding the potential of any given site.

The model is in the preliminary stages of testing, before undergoing more rigorous testing among those involved in the planning of housing developments who may or may not have some expertise of environmental design. The testing is aimed at establishing the usability of the tool, its potential and the need for further refinements and amendments.

\section{MAIN RESULTS}

A conceptual tool for the whole site appraisal of sustainable issues has been created. The tool uses passive solar design as an exemplar of a more sustainable approach to housing developments. The major result of this work was that a strategy for a framework tool, which uses a comparative analysis of different site housing options, was developed. Used at the planning stage of a housing development, it can predict the potential benefits of different alternatives from simple geometric data arranged in a series of databases.

An appropriately designed passive solar house can displace the majority of the fuel that would be used in a conventionally designed speculatively built home in the NE of Scotland, reducing dependence on fossil fuel resources. A passive solar design can reduce heating cost and achieve emission reduction of up to 70 per cent (Deveci et al., 2000) over current conventional methods of construction, although typically heating cost and 
emission reductions of around 50 per cent are achieved affordably by ensuring there is a well insulated building envelope, the required orientation is correct and overshadowing is minimised.

There are two cost significant features in a basic passive solar design, glazing and increased thermal efficiency. This research highlights the fact that savings in heating demand are achievable in a passive solar design without significant additional glazing over a standard house. The additional cost of providing a thermally efficient building envelope is, as a result of increasing thermal standards, not expensive. Successful passive solar houses have been built in the UK that do not have any significant additional cost and require no fossil fuelled heating system (Deveci et al., 2000).

The passive solar database was created by incrementally changing orientation, glazing, thermal efficiency and air-tightness. Running costs for heating will provide a maximum saving of up to 50 per cent based on just the incremental changes noted previously compared to a standard (base) housing option. An analysis of these results shows that each passive solar alternative, when compared with each other, display a remarkable consistency and that an optimised passive solar design needs only a 17-18 per cent glazing to floor area ratio to achieve maximum benefits. Ratios greater than this have similar savings in costs and emissions, however, but may suffer from peaks in under- and over-heating. Of the glazing to floor area, anywhere around 60-80 per cent is orientated to the south is preferred. Seventeen per cent glazing to floor area is quite common with most standard housing of this type having an average 15 per cent glazing to floor area ratio. This indicates that passive solar design does not need significant amounts of additional glazing, but rather needs that glazing to be re-oriented south.

There are a number of difficulties with passive solar heating when applying the principle to housing developments:

(1) Orientation can limit site layout with all the buildings required to face south - this is a problem in high northern latitudes such as the north east of Scotland. The necessary spacing between houses in northerly cities (at higher latitudes than Edinburgh) increases more rapidly for small changes to latitude.

(2) There is reluctance to change in the construction industry. In addition, changes that housing developers perceive as increasing the cost of building and potentially threatening a return on investment are, perhaps understandably, given a cautious response.

(3) Land value in most places is so high that it forces a housing developer to maximise profits through increasing density.

(4) UK Government housing targets are continually increasing, making it difficult in northern climates for passive solar design to be adopted in large, mass housing developments.

The optimum density in northern climates for passive solar designs is limited by overshadowing of obstructions within the site. A site investigation of this problem was undertaken in the North East of Scotland, with 43 sites with detached housing layouts that are either under construction or to be constructed on. Investigation of sites in the north east of Scotland highlighted that the maximum density achievable using common passive solar practice is $19 \mathrm{dph}$ (varies depending on latitude). Investigation of densities on the same sites using current methods of housing development indicates that densities are slightly higher the average being approximately 24 dwellings per hectare. This is an average across the NE of Scotland, the figure did not vary depending on latitude. 
The main conclusion from this study is that overshadowing in northern climates is such that it limits the number of houses on each site and this research has investigated how this problem may be overcome.

Various housing types were investigated for inclusion in a number of databases. 'Standard housing' was defined and investigated so that simple geometrical housing data could form a database. In addition, a passive solar database of various options was also created. The data is arranged in tabular and database format for simplified and automated extraction of data but also with a view to the future development of the tool. The databases allow selection of alternatives automatically given some basic, general specification.

The environmental site assessment strategy incorporates the capacity to establish lifecycle effects of heating costs and emissions Future developments of lifecycle costing within the model could also incorporate more cost aspects than this exemplar study provides.

\section{CONCLUSION}

The environmental site assessment is a planning decision making tool which assesses various environmental criteria against current methods of construction and advises as to the potential of environmental alternatives given the site density required by the developer. The input data is basic, resulting in simple geometric housing shapes being used to represent a typical home. These are derived from analysis of standard housing types in Scotland. The databases are an important part of the tool using information on housing, such as costs and sizes that can be displayed simply and automated.

In summary, a framework tool for the comparison of environmental sites, using passive solar design as an exemplar, has been developed. The tool uses current methods of development for comparison against passive solar layouts and establishes the need for trade-offs to meet the objectives of housing developers (to encourage use of environmental designs). It has the potential to make housing developments more sustainable and, hopefully, improve housing quality. In this, the tool developed works and is user friendly.

One aim of the tool is to clarify the increasingly complex area of environmental housing design and the wider issues of sustainability and to ensure the adoption of such a tool through the planning stages of a housing development. A method for encouraging the adoption of a tool such as this could be through the planning permission stage, where, arguably, if a housing development meets the environmental criteria set by the tool, the speed of planning permission is increased.

Future development of the tool will see wider environmental issues included, using the methodology described in this paper. In addition, further investigation of the non-financial aspects of environmental issues (Kishk and Pollock, 2005) will be included in future developments of this tool. Data representation of the outputs from the tool also needs further exploration in regards to aesthetics and the dissemination of information.

The tool, in summary, is a comparative tool. Rather than telling a planner of housing developments 'what to do' it informs the user as to the alternatives available. It is hoped, therefore, that it will not inhibit good design. In this format, it can also be used as a foundation for, and encourage, further discussions between housing developers and planning departments. The tool recognises the need for the developer to meet density and land value needs but encourages and details the necessary information to encourage a more sustainable approach to housing, which the government and local planning authorities, as their representatives, aim to increasingly adopt to meet their wider 
environmental agendas. It is also hoped that the tool will promote good planning policy with healthy and sustainable housing developments. The main beneficiary will be, of course, the home owner.

\section{References}

Balcomb, J.D. (1992) Passive Solar Buildings, MIT Press, Cambridge, MA.

Blackler, Z. (2002) 'TCPA document points finger at bad design', The Architects' Journal, www.ajplus.co.uk, 27th September 2002 at 11:44

Bordass, B. (2000) 'Cost and value: fact and fiction', Building Research and Information, 28(5/6), 338-352.

Borer, P. and Harris, C. (1998) The Whole House Book, The Centre for Alternative Technology Publications, Powys, UK. Building Research Energy Conservation Research Unit (BRECSU) (1995) 'Passive Solar House Design: Barrat Study', General Information leaflet 22, Best Practice Programme, Energy Efficiency Office, Department of the Environment.

Building Research Energy Conservation Research Unit (BRECSU) (1997) 'Passive Solar House Design — The Farrans', General Information leaflet 25, Study, Best Practice Programme, Energy Efficiency Office, Department of the Environment.

Cullingworth, B. and Nadin, V. (2002) Town and Country Planning in the UK, 13th edn, Routledge, London.

Department of the Environment, Transport and Regions (DETR) (1996) Urbanisation in England, The Stationary Office Books, London.

Department of the Environment, Transport and Regions (DETR) (1999) Towards an Urban Renaissance, Office of the Deputy Prime Minister (ODPM), (DETR), Routledge, London.

Department of the Environment, Transport and Regions (DETR) (2000) Building A Better Quality of Life: A Strategy for More Sustainable Construction, The Stationary Office Books, London.

Department of Trade and Industry (DTI) (1999) 'New and renewable energy: Prospects for the 21st century', Department of Trade and Industry (Internet), available from http://www.dti.gov.uk/renew/policy/ (Date visited: 23/10/02, 14:02).

Department of Trade and Industry (DTI) (2000) 'Passive solar design: new \& renewable energy programme', Department of Trade and Industry (Internet), available from: http://www.dti.gov.uk/renewable (Date Visited: 19/02/01 16:19).

Deveci, G., Scott, J., Edge, M. and Martin, P. (2000) 'Towards Zero-Heating: Affordable Models for Environmentally Friendly Housing in Scotland', in Laying Siege to Toytown, RIAS, Conference paper, Dundee.

Edwards, B. and Pawley, M. (2000) 'Sustainability: Today's agenda for tomorrow - Part 1', Architect's Journal, 212(1), $41-44$.

European Commission (EC) (2000) 'Towards a European strategy for the security of energy supply', Commission of the European Communities, The European Commission, Brussels (Internet), available from http://europa.eu.int/ comm/dgs/energy_transport/index_en.html (date visited:- 21/02/01 11:06).

Kachadorian, J. (1997) The Passive Solar House: Using Solar Design to Heat and Cool Your Home, Chelsea Green Publishing Company, Canada.

Kirk, S. and Dell'isola, A. (1995) Life Cycle Costing for Design Professionals, McGraw-Hill, New York.

Kishk, M. (2002) 'Towards effective consideration of non-financial factors in the design and management of construction assets', Journal of Financial Management of Property and Construction, 7(3), 163-173.

Kishk, M. and Pollock, R. (2005) 'An integrated whole-life based decision-making framework for renewable energy applications', in The Proceedings of The World Renewable Energy Congress (WREC05), Aberdeen, 22-27 May, pp. 120-125.

Marsh, R., Lauring, M. and Petersen, E.H. (2001) 'Passive solar energy and thermal mass: the implications of environmental analysis', Environmental Design, $A R Q, 5(1), 79-89$.

Tufte, E.R. (2001) The Visual Display of Quantitative Information, 2nd edn, Graphic Press, Connecticut.

Turrent, D., Doggett, J. and Ferraro, R. (1981) 'Passive solar housing in the UK, a report for the Energy Technology Research Unit, Energy Conscious Design, Milton Keynes.

Yannas, S. (1994a) Solar Energy and Housing Design, Vol. 1: Principles, Objectives, and Guidelines, Architectural Association.

Yannas, S. (1994b) Solar Energy and Housing Design, Vol. 2: Examples, Architectural Association. 